\title{
Beeldhouwwerk \\ van Jacobus Berger \\ in de Brugse St.-Donaas- \\ en St.-Salvatorskerken.
}

Over de Brugse beeldhouwer Jacobus Berger staat niet zo heel veel bekend. Hij leverde in $1777 / 78$, samen met schijnwerker Jaak van Gorp, voor de St.Annakerk, twee biechtstoelen met het bijhorend muurbeschot ${ }^{1}$. Ook de muurbekleding aan de zuidwand, vanaf de koorafsluiting tot aan de predikstoel, zou door hen gemaakt zijn². J. Gailliard schrijft eveneens de kerkmeestersbank toe aan van Gorp en Berger $^{3}$.

1. J. GAILLIARD, Ephémérides brugeoises, ou relation chronologique, Brugge, 1847, blz. 276, met rekeningenuittreksels, evenwel zonder datering. - J. Buysschaert, St.-Annakerk, Brugge (z.j.-1948) en J. Haentjens, St.-Anna Brugge. Parochie en Kerk, Brugge, 1966, geven als datum 1677/78 en als schrijnwerker Jaak van Gorp aan. J. Weale, Bruges et ses environs, Brugge, 1884, vermeldt als schrijnwerker Jan de Sangher en het jaar 1699. Dit jaartal werd nageschreven door K. De Flou, Promenades dans Bruges, Luik, 1904, en Ad. Duclos, Bruges histoire et souvenirs, Brugge, 1910 - E. Rabbaey, Brugge en omstreken, Brugge 1918, schrijft de biechtstoelen toe aan schrijnwerker Jan van Gorp (1677). V. Vermeersch, Brugges Kunstbezit, dl. 1 Brugge 1969, dateert de biechtstoelen 1677-85 en vermeldt eveneens Jan van Gorp. Zou Jaak van Gorp soms niet de vader geweest zijn van Jan van Gorp die we verder ontmoeten?

2. J. BUYSSCHAERT, a.w. blz. 21, en J. HAENTJENS, a.w. blz. 23, schrijven dat de muurbekleding vanaf de predikstoel tot aan de einddeur, in 1713 afgewerkt werd door van Gorp en Berger. Dit kan bezwaarlijk aangezien J. Berger reeds in 1701 overleed.

3. J. GAILLIARD, a.w. blz. 277, met rekeningenuittreksels, doch zonder datering. Volgens Buysschaert dateert de bank van de kerkmeesters uit de jaren 1664/65. Wellicht bedoelt Gailliard hier het gestoelte van de dischmeesters in 1688 geplaatst. 
Uit een betalingsvordering (Bijlage I) blijkt dat J. Berger ontwerptekeningen en beeldhouwwerk leverde voor werken uitgevoerd door schijnwerker Lodewijk Eelwout, in de kooromgang van de St.-Donaaskerk (1685/87).

Jacobus Berger werkte in 1680/82 mede aan de bouw en de versiering van het marmeren koordoksaal, ontworpen door Cornelius Verhouve, voor de St.-Salvatorskerk ${ }^{4}$. Wanneer Berger op 27 augustus 1683 in die kerk huwt met Magdalena Petyt, treedt Verhouve op als getuige ${ }^{5}$. Samen met Jan van Gorp levert hij er in 1690 de bekroning voor het nieuwe hoogaltaar (1645/48); daarna (1690/92) plaatsen zij de marmeren afsluiting rondom het hoogkoor6. Uit het bestelcontract $^{7}$ dat wij hieronder (Bijlage II) publiceren blijkt dat hij er nog voor de kapel van O.L. Vrouw van Loretto, de apostelbeelden van St.-Petrus en St.-Paulus leverde in 1694/95. Volgens Verschelde is het ook best mogelijk dat Berger de schepper is van de Smedenbank uit $1696^{8}$.

Tenslotte vervaardigt J. Berger in 1698 (?) en in 1697 de twee prachtige biechtstoelen in de noordelijke kooromgang van de Onze Lievevrouwkerk ${ }^{9}$. Op

4. K. VERSCHELDE, De kathedraal van S. Salvator te Brugge, Brugge, 1863, blz. 156.

5. L. LANNOO, De Brugse orgelbouwersfamilie Berger 1677-1845 - Licentiaatsthesis 1975 fol. 7. We zijn Steller dankbaar om zijn inlichtingen.

6. K. VERSCHELDE, a.w. blz. 155 en 157.

7. We danken de heer O. Mus, uit Ieper, die ons dit stuk uit het Rijksarchief van Brugge aanduidde.

8. K. VERSCHELDE, a.w. blz. 156. Over dit kunstwerk zie A. Schouteet, De bank van de Cavelotters (1696) in de kathedraal te Brugge, in Antiek, 4 (1969-70), blz. 482-485.

9. J. WEALE (a.w. blz. 128), AD. DUCLOS (a.w. blz. 676) en naar hen nog anderen, dateren deze biechtstoelen van 1689. Het is 
26 juli 1701 wordt Jacobus Berger begraven op St.Salvators.

$\mathrm{Na}$ deze korte uitweiding over de werklijst van J. Berger willen wij nagaan welke relatie er bestond tussen de nieuwbestelde apostelbeelden en de Lorettokapel. Wij citeren $\mathrm{K}$. Verschelde : «Bij akte van 14 november 1490 verkreeg het Broederschap van SS. Petrus en Paulus de kapel welke nu onder de naam van O.L.V. van Lorette bekend is, en den 25 januari 1489 gewijd was ${ }^{10}$. Al degene welke van dit broederschap deel maakten, moesten de reis naar Rome gedaan, en de kerk der HH. apostelen Petrus en Paulus bezocht hebben; daaruit gaf men aan de gildebroeders de naam van Romeinen" (blz. 211).

De broederschap van O.L. Vrouw van Loretto werd in de St.-Salvatorskerk opgericht ten jare 160911. "Van het tijdstip zijner instelling af, was dit broederschap met dit van SS. Petrus en Paulus verenigd. Al degenen welke ervan deel maakten hadden de reis gedaan naar Loretto of naar Rome» (Verschelde a.w. blz. 218).

De Brugse broederschap kende blijkbaar een hoge bloeiperiode. In 1644 werd voor haar kapel een nieuw altaar gemaakt waarop tussen Kerstdag en

niet onmogelijk dat de eerste biechtstoel dateert uit dit jaar. De tweede kwam er slechts in 1697 ; immers op het boek dat St. Jan in de hand houdt staat te lezen : Jacobus Berger sculptor et Ludovicus Hagheman scrinarius me fecerunt anno 1697. Reeds Gailliard (a.w. blz. 214) had deze namen opgemerkt - hij vermeldt daarbij nog zekere Bion. Deze laatste biechtstoel werd geschonken door Maria de Maecker, weduwe Jan Wauckier, wier wapen bovenaan staat afgebeeld.

10. Volgens Weale (a.w. blz. 110) werd deze kapel gebouwd in 1482-89 en overwelfd in 1556. De sluitsteen van het gewelf stelt Christus voor tussen Petrus en Paulus.

11. M. ENGLISH, Moorslede... of Brugge? in Biekorf, 1928, blz. 92-93. 
Lichtmis een schilderij met de geboorte van Christus werd aangebracht (Versch. a.w. blz. 219).

Omstreeks 1650 werden in de kapel de drie grote schilderijen opgehangen waar de legende op afgebeeld staat van het heilig huisje. In 1666 verschijnt te Brugge in vertaling het boekje (met platen) van Tursellini, De historie ende mirakelen van O.L. Vrouwe van Loretten. Het huizeken van Loretten dat ophangt aan de oostelijke pilaar van de kapel werd gemaakt «op het einde der jaren 1690» (Versch. a.w. blz. 220).

Dit alles laat de schijn dat de broederschap der Romeinen zich verdrongen moet gevoeld hebben in haar eigen kapel. Het verwondert ons dan ook niet dat gezorgd wordt voor het aanbrengen van nieuwe beelden van hun patroonheiligen Petrus en Paulus ${ }^{12}$. Ze dienden opgesteld op kraagstukken (schardousen = cartouches) en bekroond met een schelp opgehouden door een engel. Tegelijkertijd werd een nieuwe bekroning (croonement) aangebracht boven het altaar. Mich. English, die een tekening van dit altaar in zijn bezit had ${ }^{13}$, geeft er volgende beschrijving van : «En 1643 fut construit un nouvel autel à retable de marbre par Jean de Damhoudere. Des deux côtés du tableau se voyaient deux statues de grandeur nature, représentant les Saints Pierre et Paul. Le tableau était une toile d'A. Janssens et représentait l'Annonciation. Tout en haut de l'entablement il y avait une représentation sculptée de la Translation de la Sancta Casa» ${ }^{14}$.

12. Op het devotieprentje van O.L. Vrouw van Loretten in S. Salvators (1677) staan onderaan de HH. Petrus en Paulus afgebeeld en het wapen van paus Alexander VII (1655-1667).

13. Parochieblad Brugge, 6 aug. 1950.

14. La Patrie, Brugge, 18 en 25 mei 1935. - In het Parochieblad (6 aug. 1950) schrijft ENGLISH : "De bekroning van boven was gevormd door engelenfiguren die 't Heilig Huizeke of de Sancta Casa di Loretto droegen». 
Als contractant-besteller van het nieuwe beeldhouwwerk treedt op broeder Pieter Vanden Driessche, gasthuismeester van St.-Juliaans te Brugge ${ }^{15}$. Of hij een bestuursrol vervulde in de broederschap van SS. Pieter en Pauwel of van O.L. Vrouw van Loretten is ons onbekend. Dit is best mogelijk. In elk geval moet hij in Brugge een vooraanstand man geweest zijn, aangezien we hem eveneens ontmoeten bij de herbouw van de Blindekenskapel, waar hij medeondertekenaar is van de overeenkomst gesloten op 15 maart 1651, met timmerman Clemens de Prince, die het nodige hout voor de bouw leverde ${ }^{16}$.

Het barokke altaar, met het beeldhouwwerk van J. Berger, vond geen genade bij de neo-gotiekers van de vorige eeuw. "Cet autel fut abattu le 19 novembre 1889 et feu le curé Leuridan, qui abhorrait ces retables paiëns, fit détruire les statues d'apôtres» ${ }^{17}$.

A. DESCHREVEL

\section{Bijlage I}

1687

Heesch omme Jacques Bergee heescher ter eender sijde jegens ende ten laste van Lodewyck eelbout verweerder ter andere voor edele ende weerde heeren Burghmrs ende schepenen der stede van Brugghe.

Alvooren dheescher verthoont hoe den verweerder aen hem heescher deughdelick schuldigh ende ten achteren is de somme van seven ponden drije schell. vier grooten over het maecken ende leveren van diversche beeltauwerijen siraeten ende teekenijnghen volgens het extraict uut sheeschers hant boeck ten desen annexe.

15. Over deze gasthuismeester zie: J. GELDHOF, Pelgrims, dulle lieden en vondelingen te Brugge 1275-1975, Brugge 1975, blz. 60-61.

16. AD. DUCLOS, Onze Lieve Vrouwe van Blindekens te Brugge, Brugge, 1905, blz. 28.

17. M. ENGLISH, La Patrie, Brugge, a. nrs. 
Concluderen bydien dheescher tendeert ten fyne den verweerder worde gecondemneert inde betaelinghe vande vorseyde seven ponden drye schell. vier grooten afslagh eenighe leverynghe van printen ende teekenijnghen uutterlick ten segghen van mannen met costen.

Rekeninghe van Jacques Berger van beelthauwerye by hem ghemaeckt ende ghelevert aen $\mathrm{Mr}$ lodewick eelwout dienende aen het werck by den selven eelwout ghemaeckt inden omganck van St donaes en anders.

Eerst inde maent van April 1685 ghelevert vier cartousen ende vier Ionacakapiteelkens tot drye schellinghen grooten het stuck $1 \mathrm{lb} .4 \mathrm{sch} .0 \mathrm{gr}$.

Item den 9 february 1686 een teeckeninghe $0-4-0$ Item den 14 february twee frontdespiskens

tot 15 stuyvers yder

$0-5-0$

Item den 5 maerte een teeckeninge

$0-8-0$

Item den 14 maerte gherepareert een autaerken

$0-1-6$

Item den 12 april twee stucken cieraet dienende onder aen t'voornoemde werck

$0-7-6$

Item den 5 maerte 1687 twee figuren tot twee pont vyf schell, het stuck

$4-10-0$

Item den 17 april ghemaeckt vleugels ende handen aen twee engelkens

somme

7 lb.3sch.4 gr.

Daerop heeft den voornoemden eelwout my behandight sommige printen en teeckeninghen met een banckhaeck $t$ 'samen weerdigh ontrent een pont gr. vlaems.

Stadsarchief Brugge - Processen 1268/108035.

\section{Bijlage II}

Compareert Broeder $\mathrm{p}^{\mathrm{r}}$ van den driessche $\mathrm{m}^{\mathrm{r}}$ van den godtshuijsse van st. Juliens binnen Brugghe den welcken comparant heeft bekendt (soo hij dat bij desen) bestedt thebben aen Jacob bergere $\mathrm{m}^{\mathrm{r}}$ beleedthauwer deser stede, die ten desen oock mede is comparerende bekendt van den comparant aenghenomen thebben te maecken ende leveren een croonement boven den autaer die is staende in de capelle van onse vrauwe van lorretten in de collegie kercke van st salvators binnen brugghe volghens het model bij den aennemer danof ghemaeckt midtsgaeders oock twee beelden representerende st pieter ende st pauwels oock al volghens het model danof sijnde met de cherupijns coppen daerboven dienende ende 
oock de schardousen daer op de voors. appostelen sullen moeten ghestelt worden emmers alles conforme de modellen daer van sijnde, ende dat al van linde boomen ende abeelen hout alles leverbaer dat niet en is rot nochte vierich (in margine : is te weten dat alle de posteuren moeten ghemaeckt worden van lindeboomen) voor soo veele als hij aennemer tot het voors. werck sal moeten ghebruijcken roo deijlen hout, teselve sal moeten wesen sonder speck ende sonder knopen ende dat al voor de somme van veertich pondt gr. courant ghelt te betaelen bij een vierde ghereet, een vierde te kerstdach 1694 ende de twee resterende vierden tvoorschreven werck volmaeckt ende ghestelt sijnde, twelcke sal moeten gheschieden ten coste van den aennemer soo van het voeren als stellen dit alles sonder verghelt ende sal het selve werck moeten volmaeckt ende ghestelt sijn ter voors. cappelle voor onse vrauwe lichtijnghe 1695 (in margine : emmers veerthijen daechen onbegrepen) ende daer den aennemer in faulte blefve tselve werck voor den voors. tijt te volmaecken (ende) stellen sal hij verbeuren de somme van ses ponden grooten. Belovende den aennemer het voors. aenghenomen werck in den manieren voorschreven ende op den voorschreven tijt alsoo precijselick te volcommen, daer inne ende in de voors. boete verbindende sijn persoon ende goederen present ende toecommende op eerelicke ende reele executie. Bekennende den aennemer van den bestelder ontfanghen thebben thijen ponden grooten courant hiervooren ghereet besprocken passerende bij dien danof absolute quictancie met renunciatie aende exceptie van onghetelden ghelde. Actum desen 20 julij 1694 .

Brô Pieter vanden driessche

Jacques Berger 1694

Ons present

J. De Deckere dtor

Pauwels Jooris

1694

Me stipulante

R De Grave not.

1694

Rijksarchief Brugge, Fonds notariaat $n^{\circ} 266$ (Not. R. De Grave 1687-1699). 


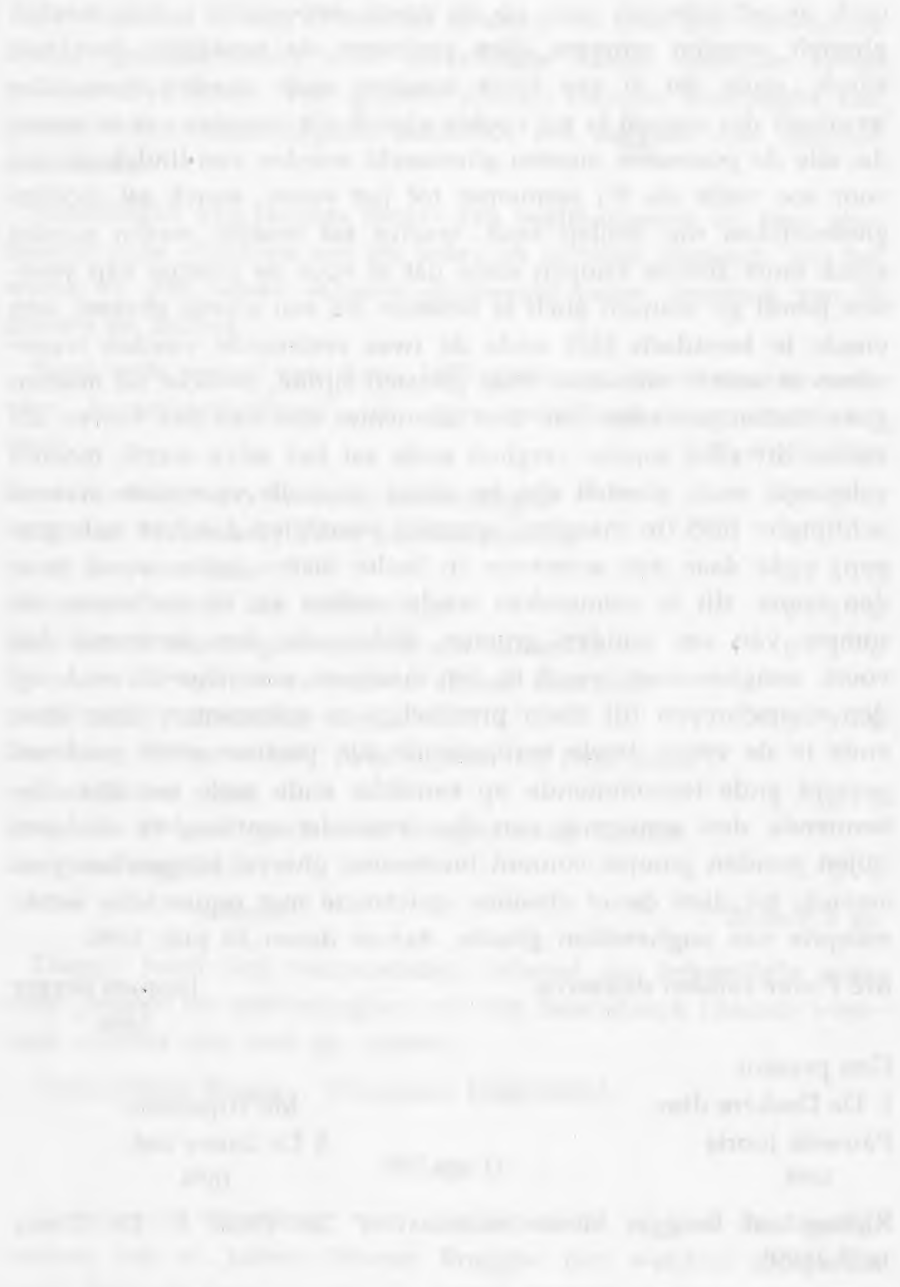

